\title{
The Professional Roles of Women Potters in Traditional Society: A Case of Erusu Akoko, Ondo State
}

\author{
O. A. Fatuyi ${ }^{1}$ \\ ${ }^{1}$ Industrial Design Department, School of Environmental Technology, Federal University of Technology, Akure
}

\begin{abstract}
Pottery is one of the traditional crafts widely practised in Nigeria even till date especially in the Southwestern part dominated by the Yoruba speaking people. There is little doubt that the professional roles that female potters take in several local communities hold social-economic importance which deserves more attention than has been accorded. This article attempts to review the state of traditional pottery production in South-western Nigeria with a special focus on a surviving pottery tradition of Erusu Akoko, Ondo state. In particular, the paper demonstrates the pottery production technique still practiced by women potters in the study area. It is observable that the current state of the craft raises grave concerns of survival as traditional potters are ageing in the face of the modern-day technology.
\end{abstract}

\section{Introduction}

The professional roles of women in the development of various African societies have been of tremendous impact even though many of them may have been largely ignored or under-appreciated. The fact remains that their contributions towards the social, economic, and political developments of the traditional society cannot be gainsaid. In various traditional African societies, the African woman possessed the power that binds the society together. It is believed that they possessed the power to organize the family and the society at large and implicitly, enormous task and responsibility are conferred on womanhood. In fact, the survival of the family and the future of marriage are depended a great deal on the African woman more so as the responsibility of both men and women were seen as complementary to one another (St. Clair, 1994: 27).

In Nigeria and particularly among the Yoruba, as it is common in Africa; pottery is widely practiced among the women, as a lucrative and viable vocation. Ukaegbe (1963: 42-45) also reported that the women in the Eastern part of Nigeria also predominate the practice like their southern counterparts and had sole prerogative to the vocation. His argument however, does not have substantive coverage over the entire nation; as it has been observed, by Adepegba (1995: 65 ) that pottery vocation is predominantly practised among the men of some Northern Nigeria states; a scenario, he affirmed was a product of their religious indoctrination.
In Yoruba land of South-western Nigeria, pottery has being one of the major vocations of the ancient that survived till date; recent archaeological finds attest to pottery practices at Iwo-Eleru dating back to as early as 8000B.C (Drewal and Schildkrout, 2010: 79). Traditionally, pottery is mainly practiced by Yoruba women; their men assist in the mining of the mineral also referred to as digging of the clay and gathering of woods for fuel needed during firing (Ibigbami, 1981:12-19). Yoruba pottery practice is traditionally a family or lineage inclination. This is a scenario where all information concerning the nitty-gritty of the vocation is concealed or sacredly kept and passed on only to members of the lineage from generation to generations and not by apprenticeship (i.e. a system of practice that encouraged training an external body, that is non member of the lineage particularly those from different background to learn vocation outside their family lineage and are required to master materials, tools, techniques, decoration and finesse). Apprenticeship however, is a recent development in Yoruba milieu as it is evident in modern pottery centres. Today, many traditional and modern pottery centres are scattered across Yoruba cities, towns and villages. They include Ibadan, Ilorin, Ipetumodu, Ile Ife, Oyo, Ogbomoso, Abeokuta, Igbara Odo, Erusu Akoko, Isua, Egbado, Ijero Ekiti, Okeho, Saki, Iseyin, Awe, Fiditi, Ilora to mention few (Kalilu, Akintonde and Ayodele, 2006; Fajuyigbe and Umoru, 2005).

It has been long observed that the role of potters in African societies has been given less attention than expected (Berns, 1989:36) probably due to issues of

This article is published under the terms of the Creative Commons Attribution License 4.0 Author(s) retain the copyright of this article. Publication rights with Alkhaer Publications. Published at: http://www.ijsciences.com/pub/issue/2019-04/

DOI: 10.18483/ijSci.1954; Online ISSN: 2305-3925; Print ISSN: 2410-4477 
social changes, gender balance in occupation and technology. Barley (1984:98-100) supports that more attention should be given to the female potter especially in West African society as they dominate the profession of pottery making which has been a rich cultural heritage where the society draws its identity and pattern of development. In view more of this, more studies that are particularistic various aspects of African pottery traditions have been encouraged especially to further promote understanding on this subject. Hence, this article attempts to review the state of traditional pottery production in South-western Nigeria with a special focus on a surviving pottery tradition of Erusu Akoko, Ondo state. In particular, the paper demonstrates the pottery production technique still commonly practiced by women potters in the study area.

\section{Women as Icons in Traditional Pottery Practices in Nigeria}

For most of the kingdoms in the pre-colonial Nigerian region, the women folk occupied an important place in the political economy of the state. They participated in various forms of economic activities including those that involved production, manufacturing, catering service as well as exchange i.e. trade and commerce. As Clarke (1972) rightly observed during his visit to Yoruba land in the 1850s, the women folk were actively involved in virtually all forms of economic activities that were conducted in the community.

The pottery industry was one of the dominant forms of indigenous industrial enterprises which predominantly engaged the services of the women folk across various communities in the pre-colonial period. The industry mostly produced both domestic and industrial utensils in clay forms which were usually fashioned into objects such as cooking pots, water cans, trays, storage tanks, weavers/dyers pots, and other items of various grades and sizes. The products also served for symbolic, spiritual and therapeutic purposes.

Some women have also been recognised for their exceptional skill and artistry. Gwari potter Ladi Kwali is an example of an iconic traditional female potter in Nigeria who embraced the contemporary technique of pottery with her indigenous style of pottery (Figure 1). Kathleen Bickford Berzock in her work "Ceramic Arts in Africa" reported the experience of the British potter Michael Cardew during his first encounter with the work of Ladi Kwali in the Gwari region of Northern Nigeria. Cardew's captivating experience was thus expressed: To watch Ladi Kwali building her pots by hand is an enlightening experience, quite as stimulating as one's first sight of a good thrower at work. You realize with surprise that it is not necessary to have a potter's wheel in order to achieve pots which have the appearance of perfect symmetry. One also experiences ... the exhilaration of watching a craftsman who seems to be doing the impossible and to be always on the brink of disaster, yet is entirely unafraid, and entirely confident with the confidence that comes from a lifetime of devotion to the craft. Crowning all this, her personal charm irradiates all her art and everything she does and seems to be the epitome of the deep-seated culture of Africa (Cardew, 1972:35).

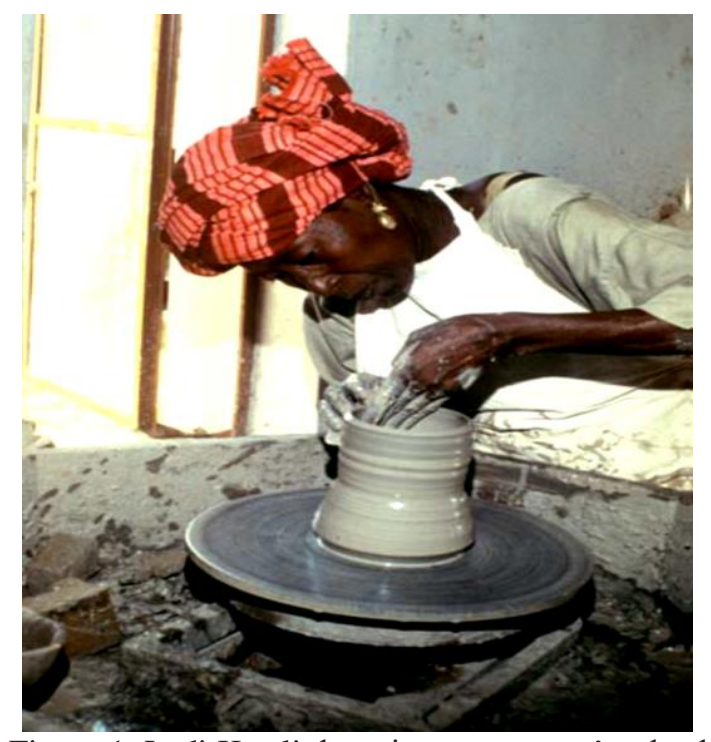

Figure 1: Ladi Kwali throwing on a potter's wheel with Cardew's influence Source: Berzock (2007)

Photograph by Michael Conner (1978)

\section{Method \\ The Study Area}

Akoko is a large Yoruba settlement in South-western Nigeria, the area extending from Ondo state to Edo state in the South Western part of Nigeria. Akoko land occupies a large chunk of the Local Government Areas in Ondo state. Among major settlements in Akoko is Erusu Akoko which is located on longitude $7^{\circ} 35^{\prime} 11.3^{\prime \prime} \mathrm{N}$ and latitude $5^{\circ} 48^{\prime} 50.0^{\prime \prime} \mathrm{E}$ under Akoko North-West Local Government Area in Ondo state, Nigeria (Figure 2). Erusu Akoko is notable as an agrarian town as well as a home to traditional pottery. It is one of the Yoruba towns in South-Western Nigeria where pottery heritage has been actively sustained till date. 


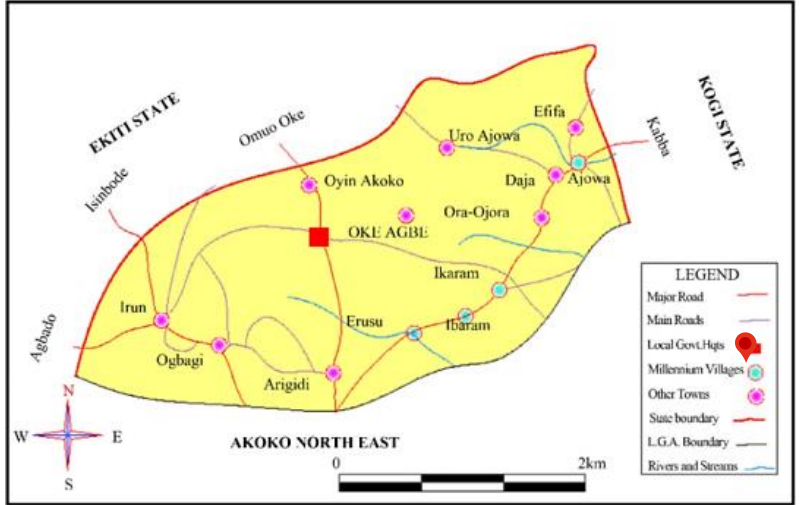

Figure 2: A map showing Erusu Akoko among surrounding towns and villages in Akoko North West, Ondo State

Source: Olajuyigbe (2016)

\section{Data Collection}

Direct field research method was employed for a careful investigation on traditional pottery practice in the study area. Oral interviews were conducted in order to elicit necessary information from local potters in the town. Visual aids such as camera were used to record photographs on the techniques, styles, and functions of potteries. Related literature materials were also consulted. The information from these literatures was used to facilitate detailed study of the pottery.

\section{A Brief Account of a Professional Traditional Potter, Madam Otun Mogaji in Erusu Akoko}

Madam Otun Mogaji is a prolific potter in Erusu Akoko, where she was born (Plate 1). Currently in her late eighties, she was observed to be a virtuoso in pottery making as evidenced in the array of pottery she makes. Suffice it to say that Madam Mogaji is one of the most promising potters of her time in Erusu Akoko.

From the information sourced from Madam Mogaji, pottery has been the main occupation of Erusu Akoko women from time immemorial. Although a greater percentage of the women in the town are potters, many of them also engage in farming and petty trading to make ends meet. In her case, she has remained a full time potter, potting throughout the year. She equally has played a leading role in coordinating the activities of other potters in the town, especially during trade fairs. She was a product of apprenticeship under Madam Dorcas Ijato. After the demise of her master in the nineties, Madam Mogaji continues practicing in Madam Ijato's pottery centre.

Madam Mogaji's works are outstanding because of the variety of pottery types as well as her creative virtuosity. Her works are classified into two groups: the common types and the unique types. The first group, that is the common types, are similar in form and function to those produced by the other potters in the town. Examples of such potteries are Ape, Oru and $А т и$. These types of pottery are ubiquitous in Yoruba pottery towns, although there exists slight local variations from one pottery centre to the other, yet they share the same characteristics in form and also perform similar functions. The Amu for example, is a water pot, usually big and spherical with height longer than the circumference. It has a neck that opens to a flared rim and functions as a vessel for storing drinking water. The second group which comprises of the unique ones are characterized by restrained ornamentation. Here emphasis is laid on form than ornaments. Conspicuous in this style are the flower vases and the decorative pots.

Mama Otun Mogaji was first a potter of the general types of pottery used as household utensils before deviating to the decorative types. The later influence in her work according to the testimony of Mama Otun Mogaji was as a result of her exposure to other Yoruba pottery traditions during cultural exhibitions and local competitions. Another factor that influenced her works is the patronage she enjoys from tourists, some of who are foreigners.

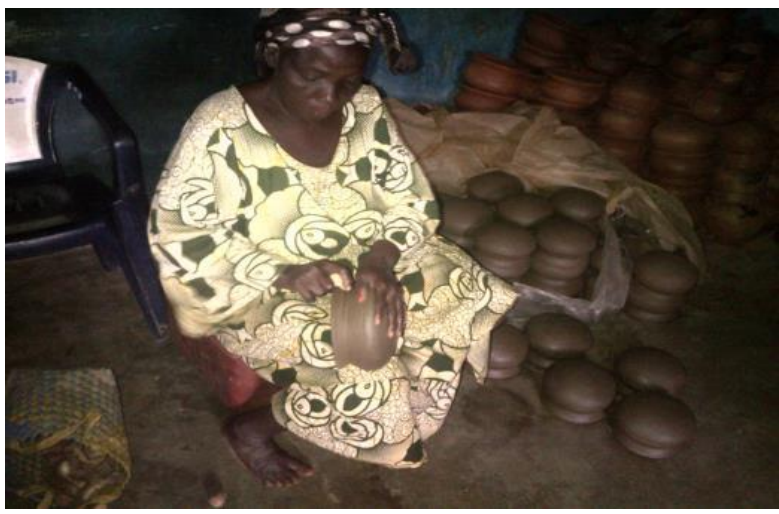

Plate 1

Mama Otun Mogaji embellishing a cooking pot (Ape)

\section{Prevailing Traditional Pottery Production Technique of Women Potters in Erusu Akoko}

It is well known that hand built technique is the method of producing indigenous wares pervasive in Yoruba land; thus is the method practiced by the potters in Erusu Akoko. Its end product is often achieved through mould, coil and pinch or the combination of the three. The implication is that throwing technique which is on potter's wheel as an alternative practise is foreign to the people. According to the potters, to make a successful hand built pottery however, three major steps or stages must be considerably explored; they are widely and 
generally considered as rim forming, body building and base forming/finishing.

The process begins with digging of clay. It was however noticed that Erusu potters use three different type of clay namely, red clay, black clay and white (gray) clay. These clays are mixed together and allowed to age before it is used (Plate 2).

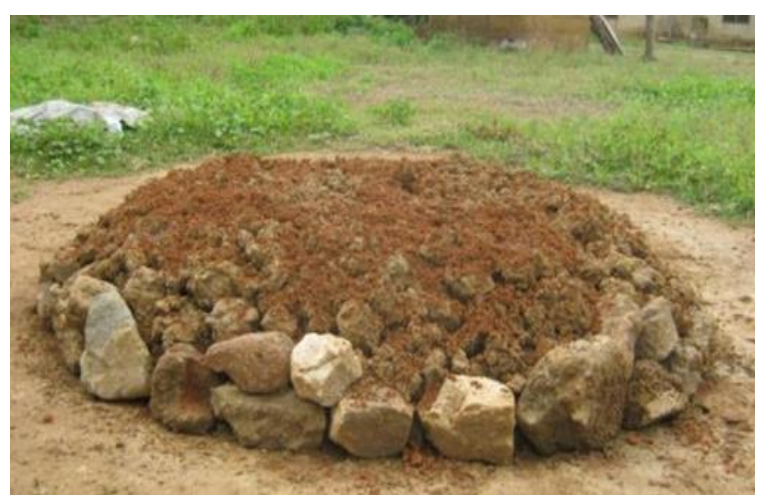

Plate 2: A pile of different clay materials collected for mixing

\section{Rim Forming}

The potter runs the tool around the rim to create circular lines (Plate 3) and leaves it to dry in the sun. Water pots are usually marked with single lines on the rim and two lines on the neck respectively. The rim of the intended pot is upturned on the potter's lap and the base is scrapped off to reveal the wet and plastic surface (Plate 4).

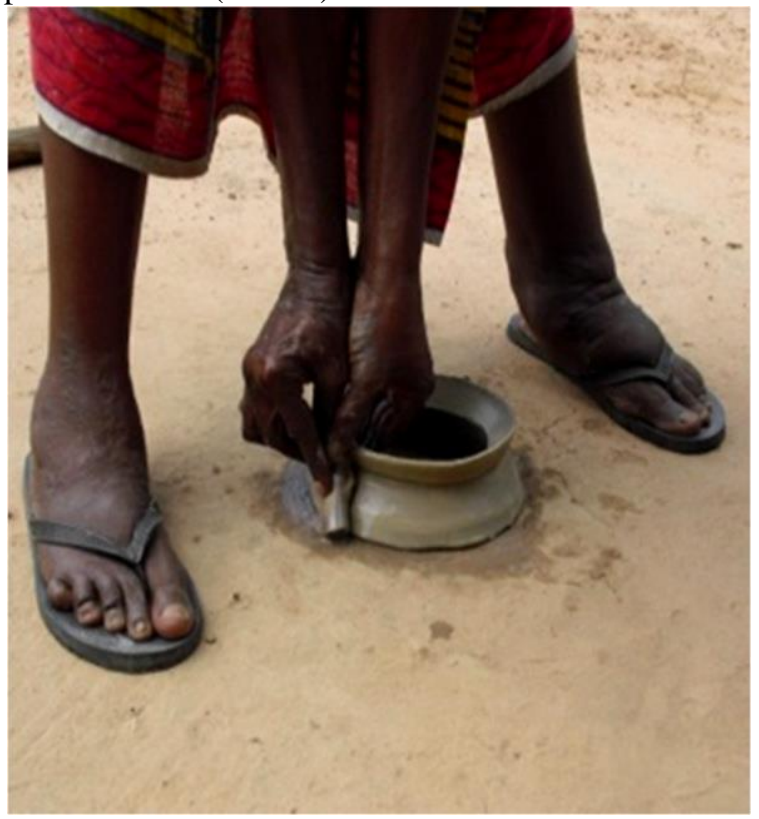

Plate 3: Shaping of rim

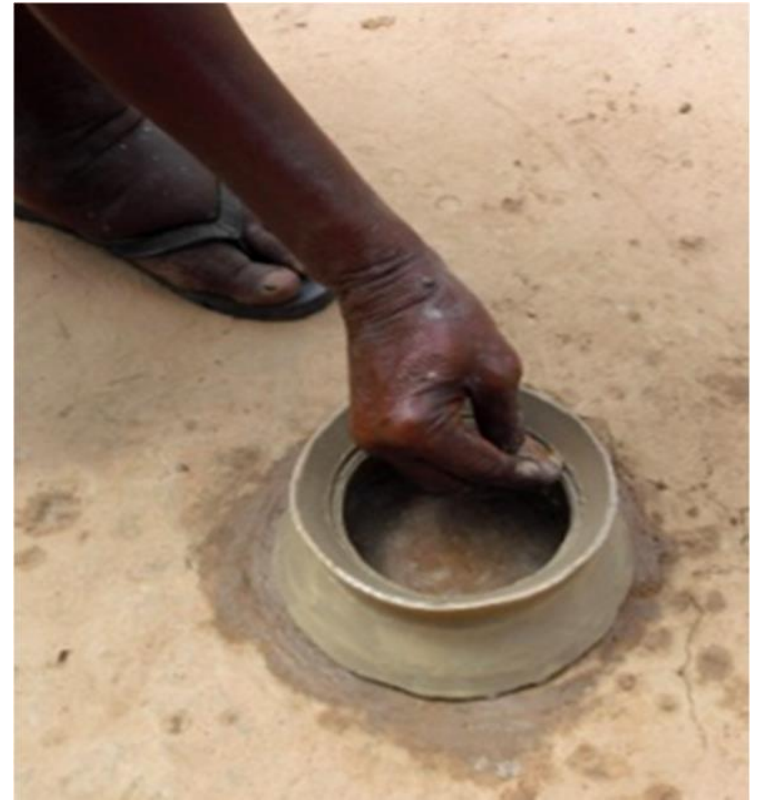

Plate 4: Formed rim with line incision

\section{Body building}

Initial modelling of the pot is done by winding a long coil of clay along the base of the rim after scraping sand from it (Plate 5). The coil is then built along the wall of the rim in an upturned position by wrapping and pressing the coil around it (Plate 6). Additional coils are laid over and pressed together one at a time and pulled to build a spherical shape (Plate 7) until the bottom is completely sealed (Plate 8).

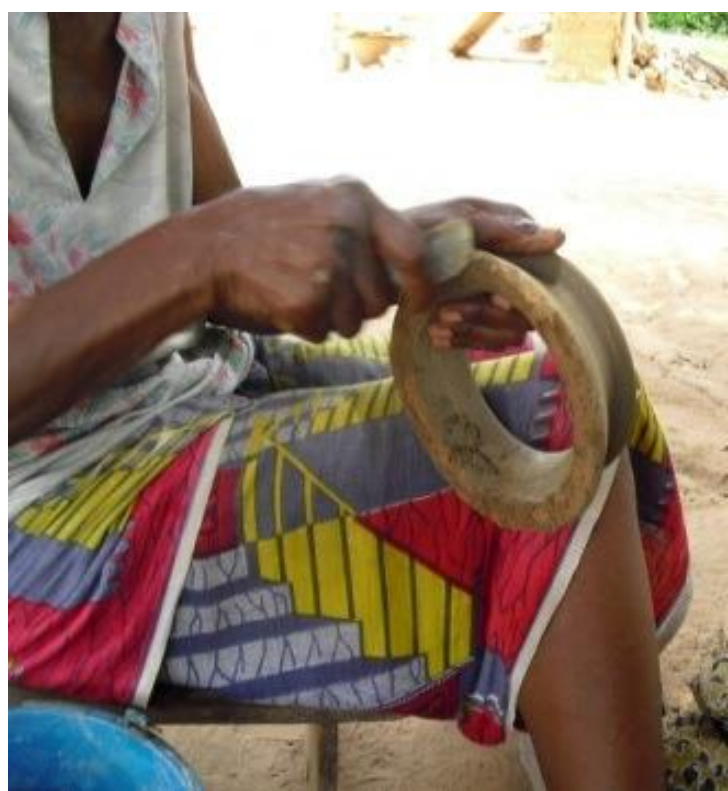

Plate 5: Scraping sand from the base of the rim 


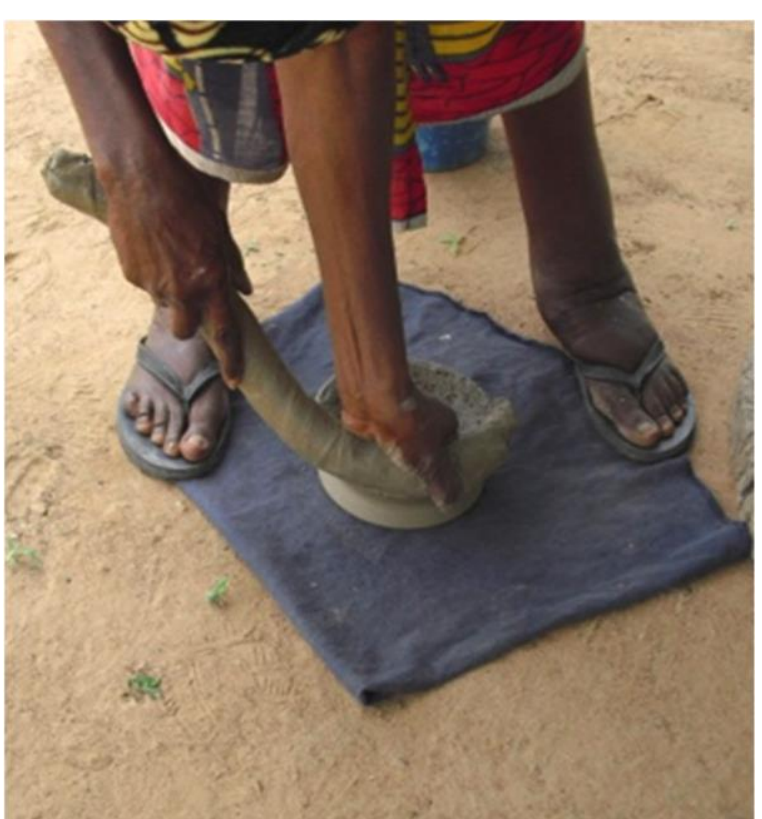

Plate 6: Adding coils

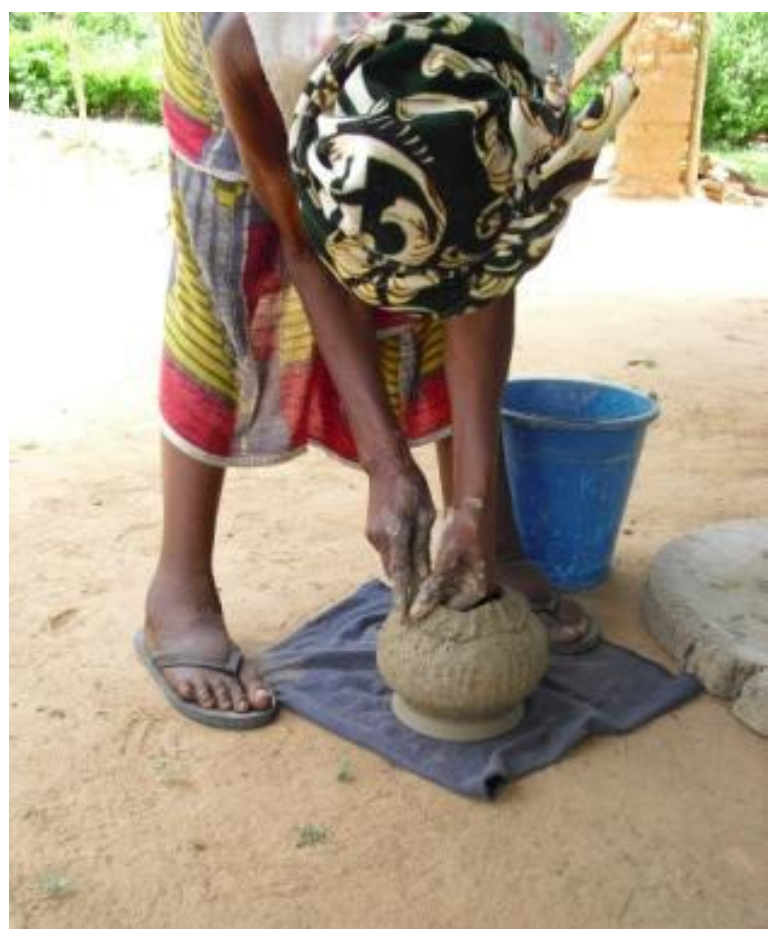

Plate 7: Pulling wall

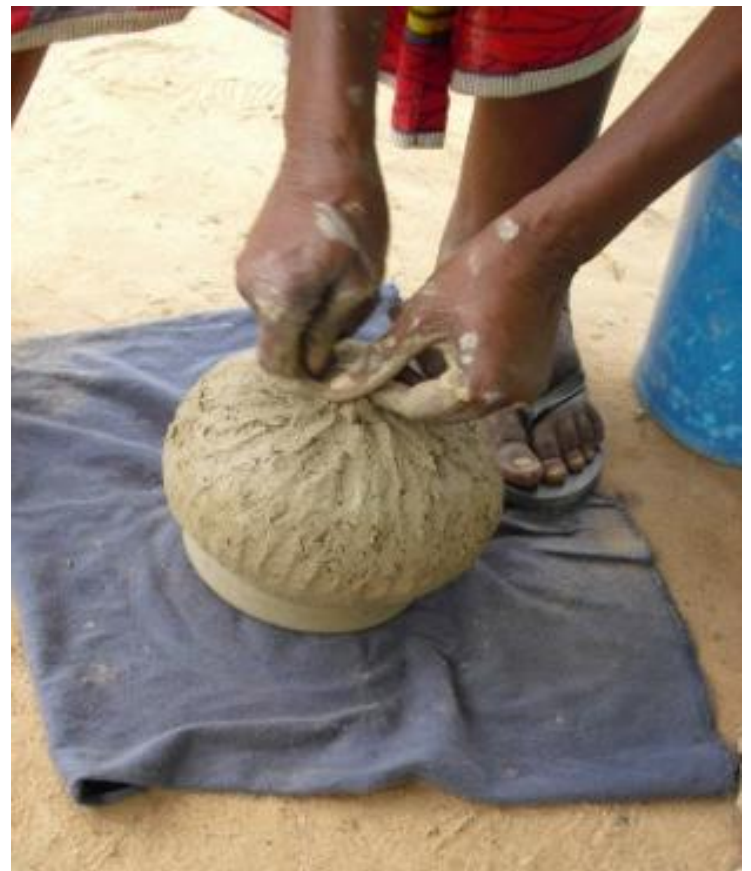

Plate 8: Sealing the bottom

\section{Base forming/ finishing}

Simultaneously, the potter gently pushes out the inner surface while beating the outer with ababe (shaping tool) to bring out the spherical shape of the pot (Plate $8)$. At the leather hard stage, the inner parts are scraped with scraper (Plate 9). Clay slip is applied to facilitate smoothening and burnishing (Plate 10).

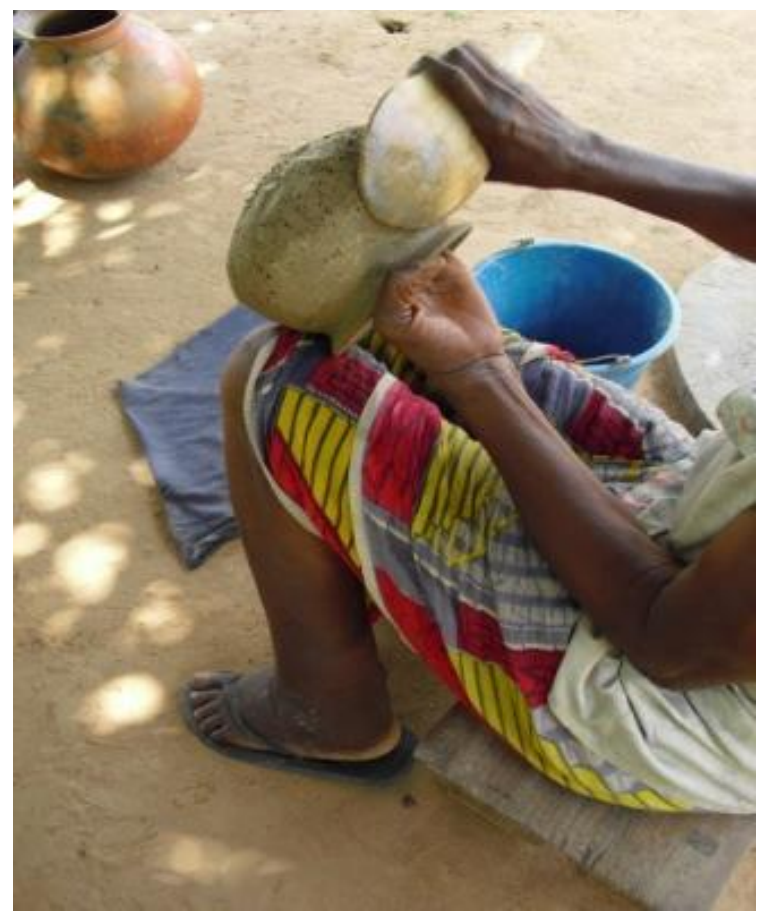

Plate 8: Smoothening the outer wall 


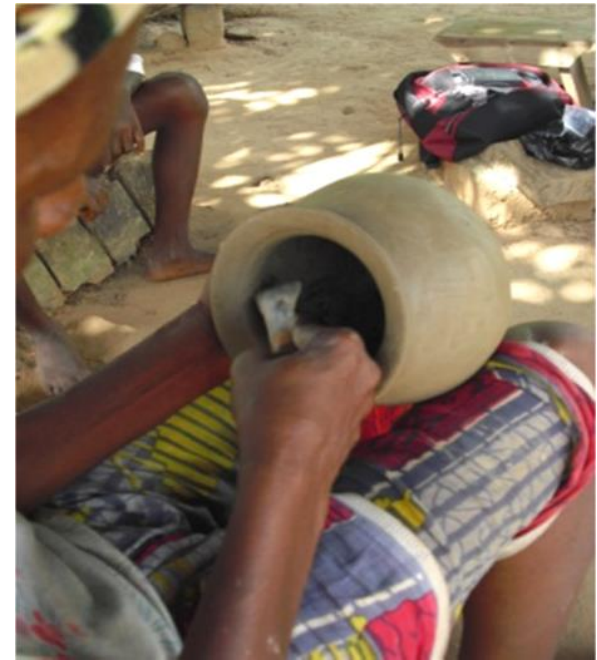

Plate 9: Scraping inner wall

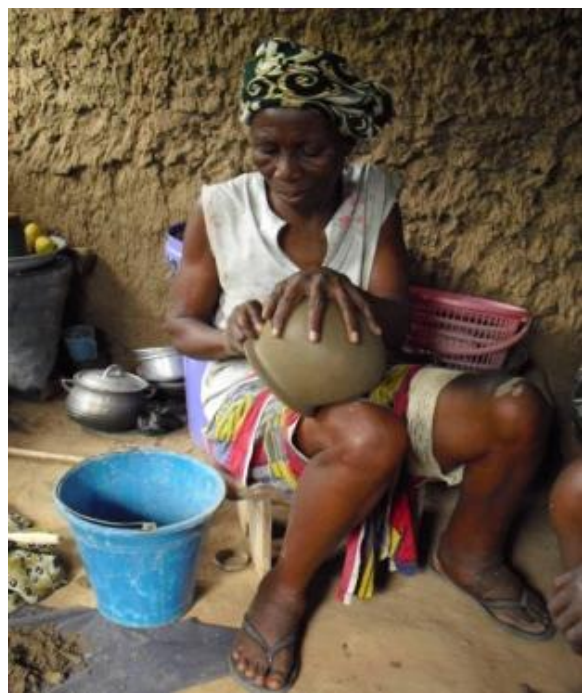

Plate 10: Burnishing the pot

Firing pots that are bone-dried is effected by the open method in which dried woods are arranged and the pots are set on it for firing (Plate 11).

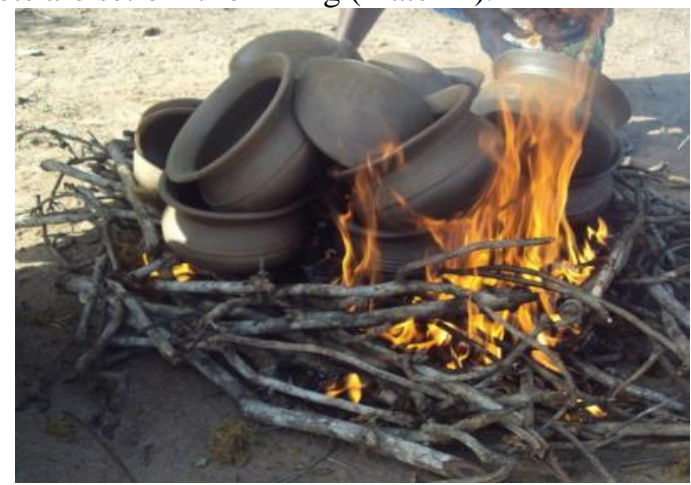

Plate 11: Dried pots fired in the open
The functional utility of the pots produced in the study area suggest the type of customs and tradition of the people. Some of the applications of utility traditional pots include cooking, fetching and storage of water, boiling local concoction and for performing traditional ritual rites.

\section{Conclusion}

In spite of the beclouded prospect for the traditional crafts, it is noteworthy that few potters in Erusu Akoko still enjoy some level of patronage because of the social-cultural significance of their products. A key challenge posed on the survival of the practice is the imminence of the potters' old age. It is indeed interesting that despite the myriad of challenges being faced by traditional pottery today, the roles played by women in the profession are undoubtedly unparalleled even in a modern day society.

\section{References}

1. Adepegba C.O. (1995). Nigerian Art: Its Traditional and Modern Tendencies. Ibadan, Nigeria: Jodad Publishers.

2. Barley, N. (1984). Placing the West African Potter. In Picton J. (ed.), Earthenware in Asia and Africa. London.

3. Berns, M.C. (1989). Ceramic Arts in Africa. African Arts, 22(2), 32-37.

4. Berzock, K.B. (2007). Ceramic Arts in Africa: A Curator's Perspective. African Arts, 40 (1), 10-17.

5. Cardew, M. (1972). "Ladi Kwale." Craft Horizons 32 (2):347.

6. Clarke, W.H. (1972). Travels and Explorations in Yoruba land, 1854-1858. J.A. Atanda (ed), Ibadan: University Press.

7. Drewal, H.J. and Schildkrout, E. (2010). Kingdom of Ife: Sculptures from West Africa. London: The British Museum Press.

8. Fajuyigbe M.O. and Umoru-Oke, N.A. (2005). The Influence of Pottery Tradition of the Department of Fine Arts, Obafemi Awolowo University, Ile-Ife: Development, Techniques and Innovation. In Aremu P.S.O. et.al (eds) Contemporary Issues in Nigeria Art: Its History and Education. Ile-Ife, Nigeria: Department of Fine Arts, Obafemi Awolowo University, 2437.

9. Gavin, R.J. (1977). The Impact of Colonial Rule on the Ilorin Economy, 1897-1930. Centre-Point Journal, 1.

10. Ibigbami, R.I. (1981). Traditional Pottery in Yoruba Culture. Black Orpheus. 4 (1): 12-19.

11. Kalilu R.O.R., Akintonde, M.A. and Ayodele, O. (2006). Ceramics: Art and Technology in the 21st Century South Western Nigeria. Agege, Nigeria: Pemilter.

12. Kashim, I.B. and Shado, A.S. (2017). Adaptation Prospects of Traditional Pottery Practice In Contemporary Erusu Akoko. International Journal of Humanities \& Social Science: Insights \& Transformations, 3 (2), 1-10.

13. Olajuyigbe, A.E. (2016). Community Participation and Sustainability Issue: An Evaluation of a Donor-Driven Water Sector in Ikaram Millenium Village Project, Nigeria. Open Journal of Social Sciences, 4(4), 90-103.

14. Saidat, A. (2011). c. 69 years, Personal Interview, OdeAfanda, Ilorin

15. St. Clair, W. (1994) Imperialism and Traditional African Culture. Cambridge: Cambridge University Press.

16. Ukaegbe, I.A. (1963). Village Pottery in Eastern Nigeria. Egg: $\quad$ Students $\quad$ Magazine. $\quad 42-\quad 45$. 